\title{
¿Qué factores hacen fallar un reimplante de cadera luego de una revisión en dos tiempos?
}

\author{
Gonzalo García-Barreiro, 'Pablo Slullitel, ' José Oñativia," Gerardo Zanotti, "Fernando Comba, \\ Francisco Piccaluga," Martín Buttaro* \\ "Centro de Cadera "Sir John Charnley", Instituto de Ortopedia y Traumatología "Prof. Dr. Carlos E. Ottolenghi", \\ Hospital Italiano de Buenos Aires, Ciudad Autónoma de Buenos Aires, Argentina \\ ${ }^{* *}$ Sanatorio del Norte, San Miguel de Tucumán, Tucumán, Argentina
}

\begin{abstract}
RESUMEN
Introducción: El objetivo del estudio fue analizar la supervivencia sin recurrencia de infección en pacientes con reemplazo total de cadera tratados con revisión en dos tiempos, valorando el impacto del cultivo intraoperatorio y la congelación positiva en el reimplante. Materiales y Métodos: Estudio retrospectivo de 96 casos con infección periprotésica crónica, según los criterios de la MusculoSkeletal Infection Society, sometidos a los dos tiempos quirúrgicos en nuestra institución, entre 2008 y 2013 . El seguimiento promedio fue 90 meses. La falla séptica se definió sobre la base de un consenso tipo Delphi modificado. La supervivencia sin falla séptica se definió sobre la base del estimador de Kaplan-Meier. Se compararon los resultados de supervivencia en función del cultivo intraoperatorio y de los estudios de anatomía patológica por congelación mediante la prueba del orden logarítmico. Resultados: La supervivencia sin falla séptica fue del 82,65\% a los 2 años (IC95\% 73,25-88,99\%), 80,40\% a los 5 años (IC95\% $70,70-87,17 \%$ ) y $77,32 \%$ a $6-10$ años (IC95\% 66,90-84,33\%). Hubo significativamente más fallas en los pacientes con un cultivo positivo en el reimplante que en aquellos con un cultivo negativo (prueba del orden logarítmico, $p=0,0208$ ), y en quienes tuvieron un estudio anatomopatológico por congelación positivo en el reimplante que en aquellos con un resultado negativo (prueba del orden logarítmico, $p=0,0154)$. Conclusiones: Los reimplantes sin recurrencias infecciosas por, al menos, 6 años tuvieron un riesgo de falla séptica muy bajo. Cuando se detectó un cultivo o una congelación positivos, la falla séptica fue significativamente mayor. Palabras clave: Infección periprotésica; reemplazo total de cadera; revisión en dos tiempos.
\end{abstract}

Nivel de Evidencia: IV

\section{What Factors Cause Hip Reimplantation to Fail after a Two-Stage Revision Hip Arthroplasty?}

\section{ABSTRACT}

Background: We analyzed the survivorship free-from-septic failure in a series of THA cases treated with a two-stage protocol at long-term follow-up, with a special focus on the relevance of positive frozen section and positive intraoperative culture taken during the reimplantation. Materials and Methods: We retrospectively reviewed data from 96 cases who met the Musculoskeletal Infection Society criteria for periprosthetic joint infection and who had undergone both stages of a two-stage protocol at our institution between 2008-2013. Mean follow-up was 90 months. Treatment failure was determined with a modified Delphi-based consensus definition. Kaplan-Meier estimate was used to determine survivorship free-from-septic failure. Log-Rank test was used to compare variables associated with septic failure. Results: Survival free-from-septic failure was $82.65 \%$ at 2 years $(95 \% \mathrm{Cl} 73.25 \%-88.99 \%)$, $80.40 \%$ at 5 years $(95 \% \mathrm{Cl} 70.70 \%-87.17 \%)$ and $77.32 \%$ at $6-10$ years $(95 \% \mathrm{Cl} 66.90 \%-84.33 \%)$. Patients with a positive culture at reimplantation had significantly more septic failures than those without it (Log-Rank test, $p=0.0208$ ), while patients with a positive frozen section at reimplantation had significantly more septic failures than those without it (Log-Rank test, $p=0.0154$ ). Conclusions: Reimplantations that remained at least 6 years without septic recurrences had a very low risk of further septic failure. Both positive frozen section and intraoperative culture at reimplantation were risk factors for septic failure.

Keywords: Periprosthetic joint infection; total hip replacement; two-stage revision surgery.

Level of Evidence: IV

Recibido el 27-2-2021. Aceptado luego de la evaluación el 26-6-2021 • Dr. GONZALO GARCÍA-BARREIRO • gonzalog.garcia@ @iba.org.ar (ID https://orcid.org/0000-0002-2729-3961 Cómo citar este artículo: García-Barreiro G, Slullitel P, Oñativia J, Zanotti G, Comba F, Piccaluga F, Buttaro M. ¿Qué factores hacen fallar un reimplante de cadera luego de una revisión en dos tiempos? Rev Asoc Argent Ortop Traumatol 2021;86(4):501-511. https://doi.org/10.15417/issn. 1852-7434.2021.86.4.1325 


\section{INTRODUCCIÓN}

A pesar de que se conoce más sobre el manejo de la infección periprotésica (IPP), la tasa de erradicación no ha cambiado en los últimos 20 años. ${ }^{1}$ Considerando que la expectativa de vida está en aumento, con un incremento sustancial en la demanda de reemplazos totales de cadera, un incremento concomitante en la incidencia proyectada de IPP significaría un problema epidemiológico grave, dados los costos en salud absorbidos por los pacientes y los sistemas sanitarios. ${ }^{2}$ La revisión en dos tiempos, en la cual la extracción y el reimplante de los componentes están separados por un tiempo con un espaciador de cemento con antibióticos, es considerada el patrón de referencia histórico para el tratamiento de la IPP. ${ }^{3}$

La tasa de éxito con este protocolo oscila entre el $65 \%$ y el $90 \%,{ }^{4,5}$ lo que muestra una amplia variabilidad en los resultados. Esto ha generado incertidumbre a la hora de entender mejor las indicaciones de revisión en dos tiempos e imprecisión en las herramientas de análisis de la eficacia del tratamiento. ${ }^{6}$

En la actualidad, no se dispone de parámetros clínicos o de laboratorio que permitan descartar la persistencia de la IPP antes del reimplante. En un intento de mejorar los resultados del tratamiento de la IPP con un protocolo en dos tiempos, varios estudios se han focalizado en detectar factores de riesgo de reinfección luego del reimplante, que incluyen variables demográficas, ${ }^{7}$ quirúrgicas ${ }^{8}$ y de laboratorio. ${ }^{9}$ Así, el rol de las secciones por congelación de anatomía patológica o de los cultivos (ya sea tomados previamente o durante el segundo tiempo) también ha sido ampliamente estudiado, pero sigue siendo un tema controvertido. ${ }^{10,11}$ Por lo tanto, la indicación de proceder con el segundo tiempo varía según cada cirujano e institución.

El objetivo de este estudio fue determinar la supervivencia sin falla séptica en una serie de pacientes con reemplazo total de cadera sometidos a una revisión en dos tiempos, valorando el impacto de un cultivo intraoperatorio o un estudio anatomopatológico por congelación positivos.

\section{MATERIALES Y MÉTODOS}

Se llevó a cabo un estudio retrospectivo de una serie consecutiva de 247 casos con IPP crónica sometidos a una revisión en nuestra institución, entre 2008 y 2013. Durante este período, 97 casos fueron tratados con un protocolo estricto de revisión en un tiempo, 30 fueron tratados con artroplastia por resección y 120 con una revisión en dos tiempos. Solo se incluyeron pacientes $>18$ años que fueron operados en dos tiempos, en nuestra institución. Se excluyó a 10 pacientes, porque no estaban aptos clínicamente para el reimplante (y permanecieron crónicamente con un espaciador) y a 13 que se perdieron en el seguimiento o que no tenían datos completos de laboratorio.

La población final del estudio incluyó 96 caderas (94 pacientes) con IPP crónica, de los cuales ocho habían tenido la cirugía primaria en nuestra institución, mientras que 88 habían sido derivados de otros centros. Se consideró como crónica a aquella IPP con una duración de los síntomas de, al menos, 6 semanas. El diagnóstico de IPP se efectuó sobre la base de los criterios de la MusculoSkeletal Infection Society (MSIS), con 1 criterio mayor o, al menos, 3 de 5 menores. ${ }^{12}$ La información sobre el tratamiento quirúrgico antes de la derivación institucional fue conseguida mediante el registro digital de la historia clínica externa.

La edad promedio en el momento del primer tiempo quirúrgico era de $63 \pm 12$ años (Tabla 1). La serie incluyó 59 mujeres y 37 hombres, con un índice de masa corporal promedio de $32 \pm 5 \mathrm{~kg} / \mathrm{m}^{2}$. La mayoría tenía una escala de la American Society of Anesthesiologists (ASA) grado 3 (58 pacientes [60\%]). Las medianas de proteína C reactiva (PCR) serológica, velocidad de eritrosedimentación y glóbulos blancos se muestran en la Tabla 1. Siete pacientes (7\%) murieron luego de los primeros dos años de seguimiento, no se produjo ninguna muerte antes de esa fecha. Todos fallecieron por causas no relacionadas con la IPP. El seguimiento promedio de la serie fue de 90 \pm 32 meses.

\section{Procedimiento quirúrgico}

La indicación de revisión en dos tiempos incluyó, al menos, dos de los siguientes factores: 1) confirmación de la IPP crónica con los criterios de la MSIS, ${ }^{12} 2$ ) pacientes funcionalmente activos, con una marcha preoperatoria independiente o con mínima asistencia, 3) presencia de fístula. En todos los casos, se utilizó un abordaje posterior en un quirófano con flujo laminar. Las cirugías estuvieron a cargo de uno de tres cirujanos especialistas en cadera. La profilaxis antibiótica preoperatoria dependió del germen aislado antes de la cirugía, si estuviere disponible; de lo contrario, se administró cefazolina 2 g por vía intravenosa. A todos se les administró una dosis preoperatoria de $1000 \mathrm{mg}$ de ácido tranexámico, y se agregó una dosis suplementaria de $1000 \mathrm{mg}$ al cierre. 
Tabla 1. Datos demográficos y cirugías de los pacientes antes del primer tiempo quirúrgico

\begin{tabular}{|c|c|}
\hline Variable & $\begin{array}{l}\text { Cantidad de caderas (total de caderas: } 96 \text {, total } \\
\text { de pacientes: } 94 \text { ) }\end{array}$ \\
\hline Edad promedio (años) & $63 \pm 12$ \\
\hline Sexo femenino $(\%)$ & $59(62,7 \%)$ \\
\hline Índice de masa corporal promedio $\left(\mathrm{kg} / \mathrm{m}^{2}\right)$ & $32 \pm 5$ \\
\hline $\begin{array}{l}\text { Escala ASA (\%) } \\
1 \\
2 \\
3 \\
4\end{array}$ & $\begin{array}{c}0(0 \%) \\
31(33 \%) \\
58(61,7 \%) \\
5(5,3 \%)\end{array}$ \\
\hline $\begin{array}{l}\text { Cirugías previas para tratar la infección periprotésica (\%) } \\
\text { Ninguna } \\
\text { Desbridamiento } \\
\text { Revisión }\end{array}$ & $\begin{array}{l}49(51 \%) \\
21(22 \%) \\
26(27 \%)\end{array}$ \\
\hline Mediana (RIC) de PCR serológica (mg/dl) & $37(22-58)$ \\
\hline Mediana (RIC) de eritrosedimentación serológica $(\mathrm{mm} / \mathrm{h})$ & $48(39-64)$ \\
\hline Mediana (RIC) de glóbulos blancos serológicos (células/ $\mu \mathrm{l})$ & $7600(6200-8950)$ \\
\hline PCR sinovial promedio $(\mathrm{mg} / \mathrm{dl})^{*}$ & $16 \pm 6$ \\
\hline Seguimiento promedio (meses) & $90 \pm 32$ \\
\hline
\end{tabular}

ASA = American Society of Anesthesiologists, RIC = rango intercuartílico; PCR = proteína C reactiva. *Analizada solo en 19 casos .

El primer tiempo consistió en la extracción, el desbridamiento periarticular profuso y la inserción de un espaciador de polimetilmetacrilato cargado con antibióticos. Para lograr una adecuada extracción del implante, se utilizó una osteotomía trocantérica extendida en 16 casos (17\%). En 68 casos (70\%), el implante, la interfase y el cemento (si hubiere) se removieron sin ningún tipo de osteotomía (Tabla 2). Se reportó una congelación intraoperatoria con inflamación aguda (positiva) en 86 casos (90\%). Desde diciembre de 2011, se empezó a medir la PCR sinovial, utilizando un valor de corte de $9,5 \mathrm{mg} / \mathrm{dl} .{ }^{13}$ En esta serie, se analizó solo en 19 casos durante el primer tiempo y el valor promedio fue de $16 \pm 6,5 \mathrm{mg} / \mathrm{dl}$.

Se usaron espaciadores no articulados en 62 casos (64\%) con vancomicina para gérmenes grampositivos y gentamicina/ceftazidima para gramnegativos. El microorganismo más frecuente fue Staphylococcus coagulasa negativo (25\%). En $10 \%$ de los casos, el cultivo fue negativo (Tabla 2).

Los defectos óseos acetabulares y femorales se clasificaron durante el primer tiempo (Tabla 2). ${ }^{14}$ Luego del espaciador, los pacientes recibieron antibioticoterapia por vía intravenosa por un tiempo promedio de $11 \pm 4$ semanas. La prescripción antibiótica dependió del germen aislado; los pacientes con infecciones con cultivo negativo recibieron tratamiento de amplio espectro (vancomicina $15 \mathrm{mg} / \mathrm{kg}$, cada $12 \mathrm{~h}$ más ceftazidima $2 \mathrm{~g}$, cada $8 \mathrm{~h} \mathrm{o}$ meropenem $1 \mathrm{~g}$, cada $8 \mathrm{~h}$ ).

La mediana entre el primero y el segundo tiempo quirúrgico fue de 97 días (rango [RIC] intercuartílico 72183). Esta variabilidad dependió de muchos factores, pero sobre todo de la autorización de los prestadores sociales. No se efectuó ninguna cirugía entre el primero y el segundo tiempo. Todos los reimplantes se realizaron con un período sin antibióticos de, al menos, dos semanas. El reimplante se efectuó a través de la misma incisión (Tabla 3).

La reconstrucción acetabular más frecuente fue con una copa primaria no cementada multiporosa (45 casos [46\%]), mientras que la femoral más habitual fue con un tallo modular, cónico de fijación distal (29 casos $[30 \%])$. 
Tabla 2. Resultados luego del primer tiempo quirúrgico

\section{Variable}

Cantidad de caderas (total de caderas: 96; total de pacientes: 94)

\section{Abordaje (\%) \\ Posterior}

$96(100 \%)$

$11(13 \%)$

$1(1 \%)$

$16(17 \%)$

$68(70 \%)$

Osteotomía trocantérica extendida

Ninguna
$62(64 \%)$
$34(36 \%)$
No articulado
Articulado

$23(24 \%)$

$25(26 \%)$

$15(15,6 \%)$

$14(14,6 \%)$

$10(10,4 \%)$

$9(9,4 \%)$

\section{Defecto óseo femoral (Paprosky) (\%)}

I

II

IIIA

IIIB

IV

Germen (\%)

Cultivo negativo

$S$. aureus resistente a meticilina

S. aureus sensible a meticilina

E. faecalis

Estafilococos coagulasa negativos resistentes a oxacilina

Estafilococos coagulasa negativos sensible a oxacilina

E. cloacae

Corynebacterium sp.

Staphyloccocus $\beta$-hemolítico

E. coli

$P$. aeruginosa

K. pneumoniae

S. viridans

Providencia sp.

Anaerobios

Polimicrobiana

Congelación positiva (\%)

Mediana de tiempo (RIC) entre el primero y el segundo tiempo (días)
$20(20,8 \%)$

$29(30,2 \%)$

$29(30,2 \%)$

$6(6,3 \%)$

$10(10,4 \%)$

$9(9,4 \%)$

$9(9,4 \%)$

$11(11,4 \%)$

$12(12,5 \%)$

$12(12,5 \%)$

$2(2,1 \%)$

$1(1 \%)$

$1(1 \%)$

$4(4,2 \%)$

$2(2,1 \%)$

$7(7.3 \%)$

$1(1 \%)$

$2(2,1 \%)$

$9(9.4 \%)$

$89(92,7 \%)$

97 (72-183)
$12(12,5 \%)$

$4(4,2 \%)$

RIC = rango intercuartílico. 
Tabla 3. Resultados luego del segundo tiempo quirúrgico

\section{Variable}

Mediana (RIC) de PCR serológica (mg/dl) antes del reimplante

$6(4-13)$

Mediana (RIC) de eritrosedimentación serológica $(\mathrm{mm} / \mathrm{h})$ antes del reimplante

$33(22-45)$

Mediana (RIC) de glóbulos blancos serológicos (células/ $\mu \mathrm{l}$ ) antes del reimplante

$6300(5000-7800)$

\section{Abordaje (\%) \\ Posterior}

$96(100 \%)$

Uso de aloinjertos (\%) para la reconstrucción acetabular o femoral

$35(36 \%)$

Reconstrucción acetabular (\%)

Copa primaria no cementada

Copa primaria cementada

$45(47 \%)$

Copa de metal trabecular/cuña

$18(19 \%)$

Aloinjertos óseos impactados

$25(26 \%)$

$8(8 \%)$

Reconstrucción femoral (\%)

Tallo primario no cementado $\quad 3(3 \%)$

Tallo primario cementado

$17(18 \%)$

Tallo no cementado, cónico, de fijación distal

$29(30 \%)$

Tallo cementado, cónico, de fijación distal

$8(8 \%)$

Tallo cementado largo, pulido, de revisión

$7(7 \%)$

Aloinjertos óseos impactados

$26(27 \%)$

Reemplazo femoral proximal

$3(3 \%)$

Compuesto de aloinjerto-prótesis

$2(2 \%)$

Reemplazo femoral total

Congelación positiva (\%)

$17(18 \%)$

Cultivo intraoperatorio positivo (\%)

Un solo cultivo positivo

$6(6 \%)$

$\mathrm{Al}$ menos, 2 cultivos positivos del mismo germen

$1(1 \%)$

$\mathrm{RIC}=$ rango intercuartílico, $\mathrm{PCR}=$ proteína $\mathrm{C}$ reactiva.

\section{Muestras intraoperatorias obtenidas durante el reimplante}

Luego de extraer el espaciador, se obtuvieron, al menos, seis muestras para congelación y cultivo. Las muestras comprendieron diversos tipos de tejido (hueso en contacto con cemento, membrana sinovial, cápsula, interfase, fluido articular) y las localizaciones fueron no estandarizadas, pero incluyeron, como mínimo, tres de la región acetabular y tres de la femoral. El valor de corte para la congelación fue como mínimo 5 polimorfonucleares en cada uno de, por lo menos, 10 campos de 400 de aumento. ${ }^{15}$

\section{Seguimiento}

Los pacientes fueron controlados a los 15 y 45 días, a los 3 meses, al año y, cada 2 años, de allí en más. El seguimiento funcional y radiológico estuvo a cargo de un ortopedista especializado y el seguimiento de laboratorio, de un infectólogo. Se realizó un análisis serológico en cada control, que incluyó PCR y eritrosedimentación. La antibioticoterapia después del reimplante duró entre 6 y 8 semanas. Los pacientes que tuvieron, al menos, un cultivo intraoperatorio positivo o presentaron inflamación aguda en la congelación del reimplante, aquellos sin una curva descendente de la eritrosedimentación y la PCR en el primer mes posoperatorio o los inmunocomprometidos recibieron antibioticoterapia extendida por un período variable, según el criterio del infectólogo y la evolución de la IPP. 


\section{Variables de resultado}

Se midió el éxito de la revisión en dos tiempos definiendo a la falla séptica después del reimplante sobre la base de los criterios del consenso internacional tipo Delphi. ${ }^{16}$ Esto incluyó parámetros clínicos (herida cerrada, sin signos de inflamación o drenaje) y quirúrgicos (cualquier cirugía efectuada por sospecha de infección) o la muerte relacionada con la IPP (es decir, sepsis). Al igual que Akgün y cols., también se consideró como falla séptica si el paciente había recibido antibioticoterapia supresora $>6$ meses. ${ }^{17}$

\section{Análisis estadístico}

Las variables continuas se expresaron como mediana y RIC o promedio y desviación estándar; y las variables categóricas, como porcentaje y frecuencia absoluta. La supervivencia sin falla séptica se calculó sobre la base del estimador de Kaplan-Meier. Se compararon los resultados de supervivencia en función del cultivo intraoperatorio y del estudio anatomopatológico por congelación mediante la prueba del orden logarítmico (log-rank test). Se consideró estadísticamente significativo un valor $\mathrm{p}<0,05$. Los análisis se efectuaron con el programa Stata 14 (Stata Corp., College Station, Texas, EE.UU.).

\section{RESULTADOS}

Se hallaron 21 fallas sépticas al final del seguimiento. La supervivencia sin falla séptica (Figura 1) fue del $89,17 \%$ al año (IC95\% 90,81-94,02\%; tasa de mortalidad 3,12\%), 82,65\% a los 2 años (IC95\% 73,25-88,99\%; tasa de mortalidad 4,5\%), 80,40\% a los 5 años (IC95\% 70,70-87,17\%; tasa de mortalidad 6,25\%) y 77,32\% a los 6-10 años (IC95\% 66,90-84,33\%; tasa de mortalidad 7,29\%).

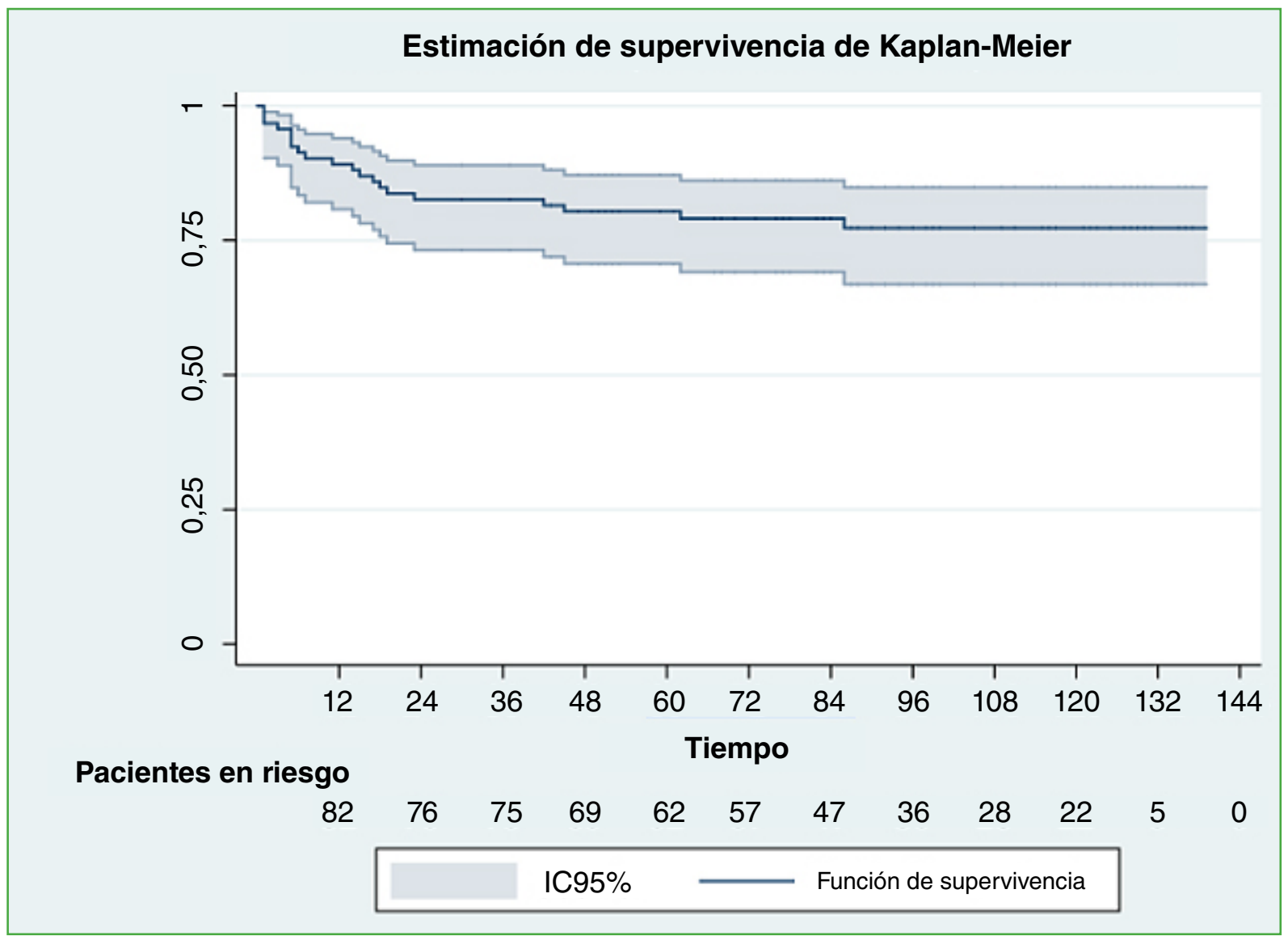

Figura 1. Gráfico de la supervivencia sin falla séptica en función del tiempo, mediante el método de Kaplan-Meier. 
Cinco de siete casos con un cultivo intraoperatorio positivo y 18 de 89 casos sin cultivos positivos tuvieron fallas sépticas. El tiempo promedio hasta la falla séptica en cada grupo fue de $8.8 \pm 9.8$ y $20 \pm 24.5$ meses, respectivamente. De igual manera, hubo fallas sépticas en 8 de 17 casos con congelación positiva y en 15 de 79 sin ella. El tiempo promedio hasta la falla séptica en cada grupo fue de $13.6 \pm 14.8$ y $18.5 \pm 25.4$ meses, respectivamente.

Al comparar la supervivencia sin falla séptica entre aquellos con un cultivo positivo y sin cultivo positivo en el reimplante, hubo significativamente más fallas en los primeros al final del seguimiento (prueba del orden logarítmico, $\mathrm{p}=0,0208)$, como se muestra en la Figura 2.

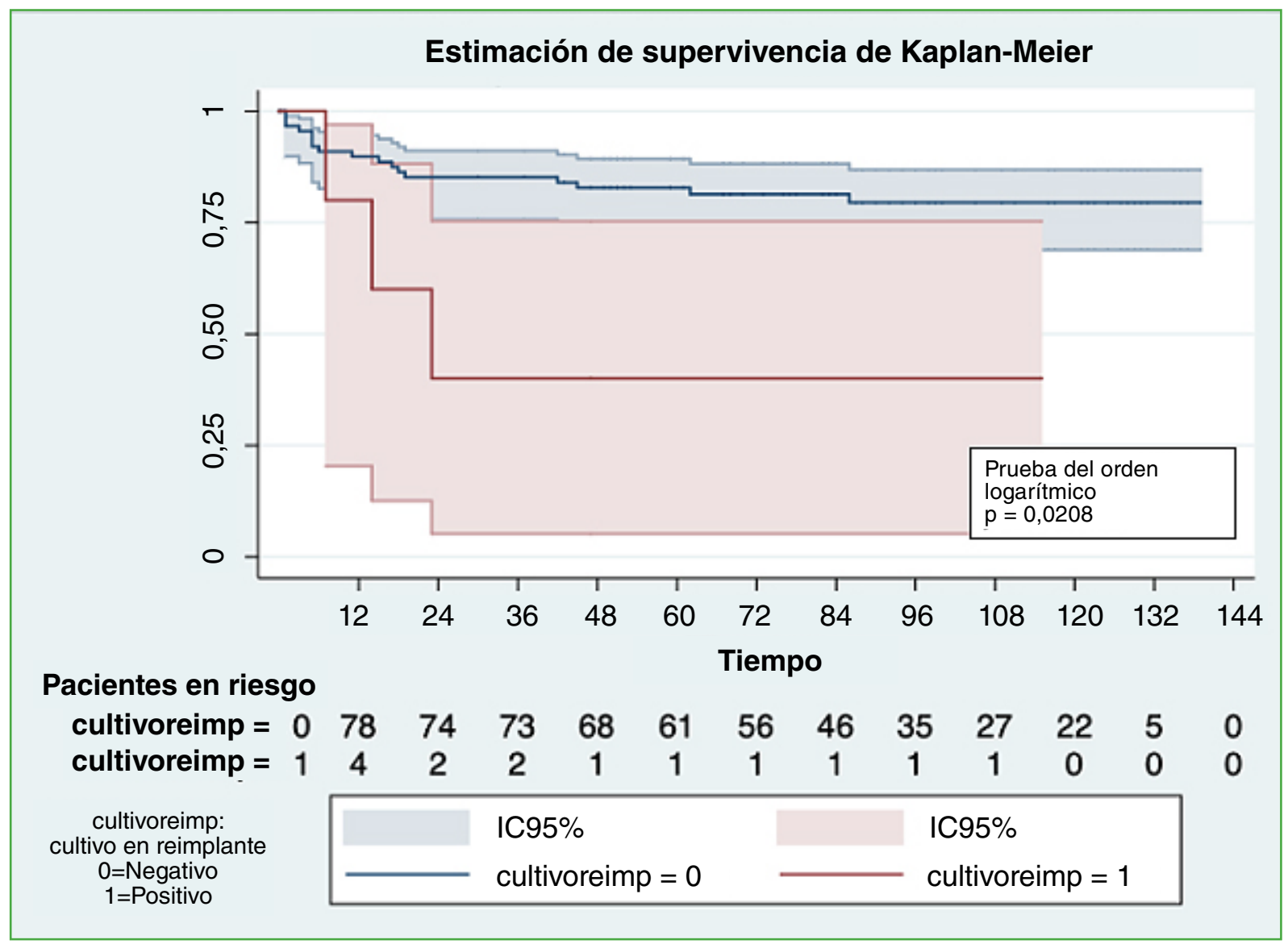

Figura 2. Gráfico de la supervivencia sin falla séptica en función del tiempo, separando a la serie en dos grupos según la presencia de un cultivo positivo durante el reimplante. Los grupos fueron comparados mediante la prueba del orden logarítmico (log-rank test).

Igualmente, al comparar la supervivencia sin falla séptica entre aquellos con un estudio anatomopatológico por congelación positivo y sin un resultado positivo en el reimplante, hubo significativamente más fallas en los primeros al final del seguimiento (prueba del orden logarítmico, $p=0,0154$ ), como se muestra en la Figura 3.

\section{DISCUSIÓN}

Diversos factores (dependientes del huésped, del médico, del germen y de la sociedad) pueden alterar la evolución natural de la IPP derivando en una falla terapéutica. En esta serie, la mayoría de las fallas sépticas ocurrieron en los primeros 6 años de seguimiento después del reimplante. Así, un reimplante que alcanzó el punto de referencia de 6 años sin ninguna reoperación por infección, tuvo muy baja probabilidad de sufrir una falla séptica en el futuro. Estos resultados concuerdan con hallazgos previos que midieron la incidencia acumulada de IPP en hasta 15 años de seguimiento. ${ }^{18}$ 


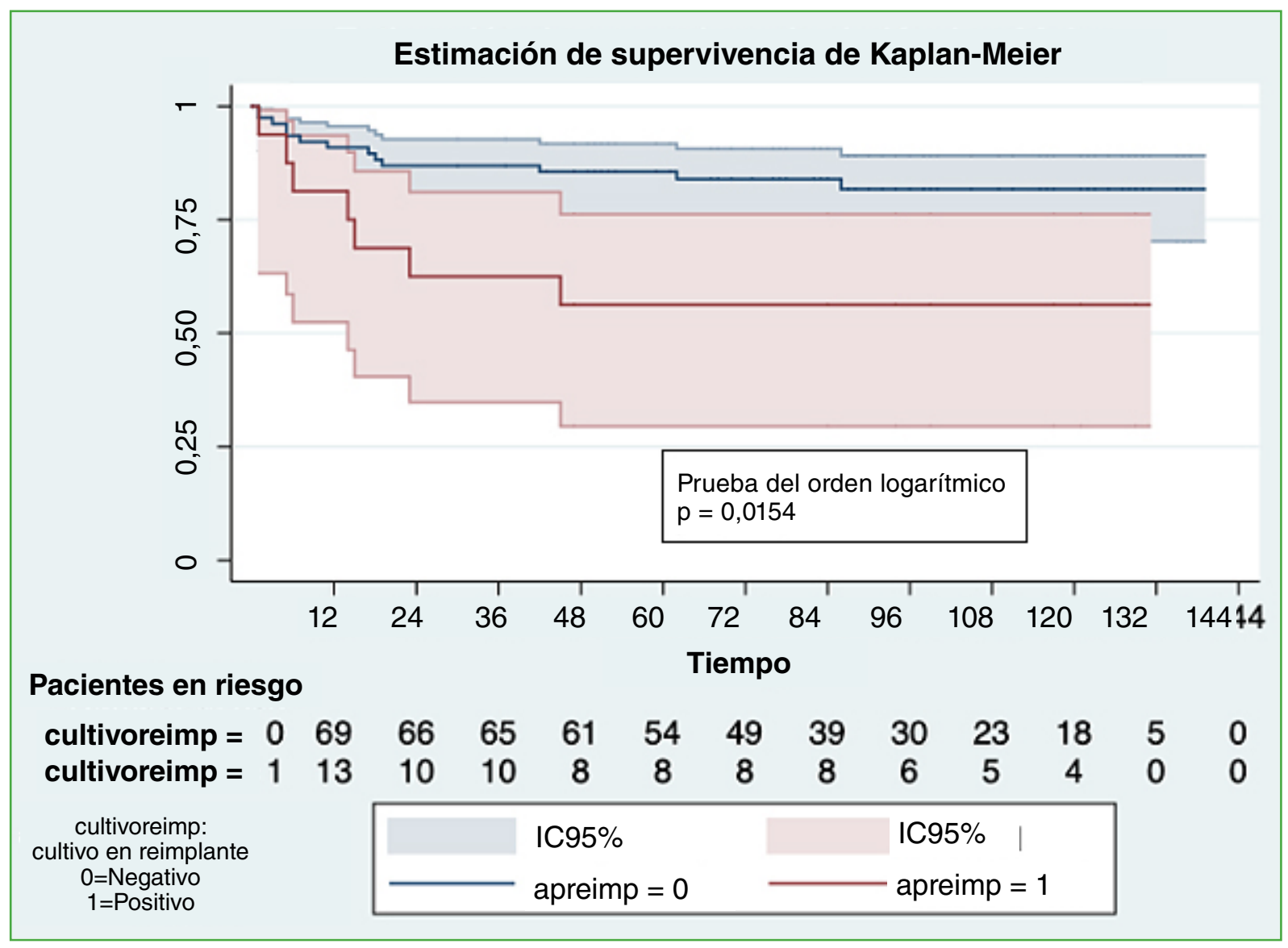

Figura 3. Gráfico de la supervivencia sin falla séptica en función del tiempo, separando a la serie en dos grupos según la presencia de un estudio anatomopatológico por congelación positivo durante el reimplante. Los grupos fueron comparados mediante la prueba del orden logarítmico (log-rank test).

Se ha comunicado escasos datos sobre los resultados a más de 5 años del reimplante, dado que las IPP recidivan, por lo general, en los primeros dos años; sin embargo, creemos que estos pacientes deben ser controlados, como mínimo, 5 o 6 años para considerar a una IPP como realmente "curada".

Nuestro estudio no estuvo exento de limitaciones. Primero, la naturaleza retrospectiva y la baja cantidad de pacientes se correlacionaron con la imposibilidad de generar un análisis de supervivencia más apropiado. No obstante, nuestra indicación de revisión en dos tiempos ha sido estricta y reproducible, con un bajo número de casos perdidos en el seguimiento y con un seguimiento promedio de 7.5 años, más prolongado que en muchos estudios similares. ${ }^{19}$ Segundo, no se ha evaluado el estado clínico de los pacientes. Se han descrito diversos puntajes (Western Ontario and McMaster Universities Osteoarthritis Index [WOMAC], University of California Los Angeles Index [UCLA], modified Harris Hip Score [mHHS]) para medir la funcionalidad de las revisiones en uno y dos tiempos. Tercero, el criterio para definir una falla séptica incluyó la antibioticoterapia supresora, y este hecho podría alterar el análisis de supervivencia. Dado que la antibioticoterapia supresora puede "estirar" la vida de un reimplante, ${ }^{20}$ el criterio del consenso tipo Delphi ${ }^{16}$ modificado que usamos puede hacer malinterpretar los resultados. No está completamente claro si los pacientes con terapia supresora deberían ser considerados fallas o bien parte de una estrategia terapéutica ideada para prevenir reintervenciones futuras. ${ }^{6}$

La evidencia actual es controvertida con respecto al significado clínico de una congelación o un cultivo intraoperatorio positivos en el reimplante. En 2018, el International Consensus Meeting para el tratamiento de las IPP resolvió que existe evidencia limitada (consenso débil) para utilizar la congelación intraoperatoria para la toma de decisiones en el reimplante. ${ }^{21}$ Se ha demostrado que la congelación es altamente específica, pero poco sensible para 
detectar la persistencia de IPP, ${ }^{10,11}$ por lo que es poco fiable. Asimismo, es un estudio dependiente del patólogo, no está disponible en varios centros por ser costosa en nuestro medio y sus valores de corte varían según las diversas instituciones. La congelación es un estudio que podría guiar hacia un reimplante seguro, a diferencia de los parámetros serológicos o sinoviales que son ineficaces en presencia de un espaciador. ${ }^{9}$

La validez de los criterios MSIS para su uso en los reimplantes no es clara. Tener dos cultivos positivos del mismo germen es un criterio mayor para diagnosticar IPP, ${ }^{12}$ pero el poder diagnóstico de los cultivos entre las dos etapas del tratamiento (es decir, con el espaciador) es limitado por dos razones. Primero, la presencia de un espaciador afecta la sensibilidad de los cultivos si se tomaran como una biopsia aspirativa antes de la cirugía. Los resultados falsos negativos, reportados hasta casi en un 15-25\%, pueden subestimar la persistencia de la IPP. ${ }^{22}$ Segundo, los cultivos intraoperatorios solo están disponibles luego del reimplante, y las técnicas de tinción de Gram aisladas también tienen muy poca sensibilidad. ${ }^{23}$ Sin embargo, los cultivos sí pueden predecir fallas sépticas. Akgün y cols. ${ }^{17}$ comunicaron una tasa de falla más alta en casos con un único cultivo positivo, y sugieren, al igual que en nuestro estudio, antibioticoterapia extendida en esos casos.

Este hecho invoca a técnicas más eficientes de tipificación bacteriana antes del reimplante. La sonicación y el secuenciamiento genético de última generación podrían llegar a optimizar el poder de identificación bacteriana, pero la evidencia sobre ellos es muy controvertida como para indicarlos en forma rutinaria. La prueba ADNr 16s que combina reacción en cadera de la polimerasa con flujo lateral inmunocromatográfico se ha propuesto como un método intraoperatorio novedoso para aislar bacterias en tan solo 25 minutos. ${ }^{24,25}$ Sin embargo, su uso no está disponible en todo el mundo y aún resta probar su costo-efectividad.

\section{CONCLUSIONES}

No se ha descrito superioridad alguna de un parámetro sobre otro a la hora de predecir el momento ideal para reimplantar. En la toma de decisiones, se deberían contemplar diversos factores, inclusive signos y síntomas, adherencia y respuesta al tratamiento antibiótico, y resultados de laboratorio serológico, sinovial y de anatomía patológica. En definitiva, este estudio demostró que los estudios de anatomía patológica por congelación positivos y un cultivo intraoperatorio positivo se asociaron a recurrencia de la IPP a mediano y largo plazo. Mientras que la congelación puede utilizarse como un parámetro válido para diferir un reimplante y sugerir una reindicación del primer tiempo, el cultivo tiene, por lo pronto, solo un valor pronóstico. Finalmente, nuestros resultados de supervivencia sugieren que si un reimplante permanece, al menos, 6 años sin recurrencias infecciosas, el riesgo de falla séptica futura es bajo.

Conflicto de intereses: Los autores no declaran conflictos de intereses.

ORCID de P. Slullitel: https://orcid.org/0000-0002-8957-075X ORCID de J. Oñativia: https://orcid.org/0000-0001-8534-5101 ORCID de G. Zanotti: https://orcid.org/0000-0001-8090-4832
ORCID de F. Comba: https://orcid.org/0000-0002-2848-2983

ORCID de F. Piccaluga: https://orcid.org/0000-0002-9887-4886 ORCID de M. Buttaro: https://orcid.org/0000-0003-3329-778X

\section{BIBLIOGRAFÍA}

1. Xu C, Goswami K, Li WT, Tan TL, Yayac M, Wang S-H, et al. Is treatment of periprosthetic joint infection improving over time? J Arthroplasty 2020;35(6):1696-1702. https://doi.org/10.1016/j.arth.2020.01.080

2. Kurtz SM, Lau E, Watson H, Schmier JK, Parvizi J. Economic burden of periprosthetic joint infection in the United States. J Arthroplasty 2012;27(8):61-65.e1. https://doi.org/10.1016/j.arth.2012.02.022

3. Matthews PC, Berendt AR, McNally MA, Byren I. Diagnosis and management of prosthetic joint infection. BMJ 2009;338:b1773. https://doi.org/10.1136/bmj.b1773

4. Berend KR, Lombardi AV, Morris MJ, Bergeson AG, Adams JB, Sneller MA. Two-stage treatment of hip periprosthetic joint infection is associated with a high rate of infection control but high mortality. Clin Orthop Relat Res 2013;471(2):510-8. https://doi.org/10.1007/s11999-012-2595-X 
5. Wang Q, Goswami K, Kuo F-C, Xu C, Tan TL, Parvizi J. Two-stage exchange arthroplasty for periprosthetic joint infection: the rate and reason for the attrition after the first stage. J Arthroplasty 2019;34(11):2749-56. https://doi.org/10.1016/j.arth.2019.06.021

6. Tan TL, Goswami K, Fillingham YA, Shohat N, Rondon AJ, Parvizi J. Defining treatment success after 2-stage exchange arthroplasty for periprosthetic joint infection. J Arthroplasty 2018;33(11):3541-6. https://doi.org/10.1016/j.arth.2018.06.015

7. Watts CD, Wagner ER, Houdek MT, Osmon DR, Hanssen AD, Lewallen DG, et al. Morbid obesity: a significant risk factor for failure of two-stage revision total knee arthroplasty for infection. J Bone Joint Surg Am 2014;96(18):e154-1-7. https://doi.org/10.2106/JBJS.M.01289

8. Corona PS, Barro V, Mendez M, Cáceres E, Flores X. Industrially prefabricated cement spacers: do vancomycinand gentamicin-impregnated spacers offer any advantage? Clin Orthop Relat Res 2014;472(3):923-32. https://doi.org/10.1007/s11999-013-3342-7

9. Frangiamore SJ, Siqueira MBP, Saleh A, Daly T, Higuera CA, Barsoum WK. Synovial cytokines and the MSIS criteria are not useful for determining infection resolution after periprosthetic joint infection explantation. Clin Orthop Relat Res 2016;474(7):1630-9. https://doi.org/10.1007/s11999-016-4710-x

10. Della Valle CJ, Bogner E, Desai P, Lonner JH, Adler E, Zuckerman JD, et al. Analysis of frozen sections of intraoperative specimens obtained at the time of reoperation after hip or knee resection arthroplasty for the treatment of infection. J Bone Joint Surg Am 1999;81(5):684-9. https://doi.org/10.2106/00004623-199905000-00009

11. George J, Kwiecien G, Klika AK, Ramanathan D, Bauer TW, Barsoum WK, et al. Are frozen sections and MSIS criteria reliable at the time of reimplantation of two-stage revision arthroplasty? Clin Orthop Relat Res 2016;474(7):1619-26. https://doi.org/10.1007/s11999-015-4673-3

12. Parvizi J, Gehrke T. Definition of periprosthetic joint infection. J Arthroplasty 2014;29(7):1331. https://doi.org/10.1016/j.arth.2014.03.009

13. Buttaro MA, Martorell G, Quinteros M, Comba F, Zanotti G, Piccaluga F. Intraoperative synovial C-reactive protein is as useful as frozen section to detect periprosthetic hip infection. Clin Orthop Relat Res 2015;473(12):3876-81. https://doi.org/10.1007/s11999-015-4340-8

14. Aribindi R, Barba M, Solomon MI, Arp P, Paprosky W. Bypass fixation. Orthop Clin North Am 1998;29(2):319-29. https://doi.org/10.1016/s0030-5898(05)70330-8

15. Nuñez LV, Buttaro MA, Morandi A, Pusso R, Piccaluga F. Frozen sections of samples taken intraoperatively for diagnosis of infection in revision hip surgery. Acta Orthop 2007;78(2):226-30. https://doi.org/10.1080/17453670710013726

16. Diaz-Ledezma C, Higuera CA, Parvizi J. Success after treatment of periprosthetic joint infection: a Delphi-based International Multidisciplinary Consensus. Clin Orthop Relat Res 2013;471(7):2374-82. https://doi.org/10.1007/s11999-013-2866-1

17. Akgün D, Müller M, Perka C, Winkler T. A positive bacterial culture during re-implantation is associated with a poor outcome in two-stage exchange arthroplasty for deep infection. Bone Joint J 2017;99-B(11):1490-5. https://doi.org/10.1302/0301-620X.99B11.BJJ-2017-0243-R1

18. Petis SM, Abdel MP, Perry KI, Mabry TM, Hanssen AD, Berry DJ. Long-term results of a 2-stage exchange protocol for periprosthetic joint infection following total hip arthroplasty in 164 hips. J Bone Joint Surg Am 2019;101(1):74-84. https://doi.org/10.2106/JBJS.17.01103

19. Leonard HAC, Liddle AD, Burke O, Murray DW, Pandit H. Single- or two-stage revision for infected total hip arthroplasty? A systematic review of the literature. Clin Orthop Relat Res 2014;472(3):1036-42. https://doi.org/10.1007/s11999-013-3294-y

20. Siqueira MBP, Saleh A, Klika AK, O'Rourke C, Schmitt S, Higuera CA, et al. Chronic suppression of periprosthetic joint infections with oral antibiotics increases infection-free survivorship. J Bone Joint Surg Am 2015;97(15):122032. https://doi.org/10.2106/JBJS.N.00999

21. Aalirezaie A, Bauer TW, Fayaz H, Griffin W, Higuera CA, Krenn V, et al. Hip and Knee Section, Diagnosis, Reimplantation: Proceedings of International Consensus on Orthopedic Infections. J Arthroplasty 2019;34(2):S36979. https://doi.org/10.1016/j.arth.2018.09.021

22. Ghanem E, Azzam K, Seeley M, Joshi A, Parvizi J. Staged revision for knee arthroplasty infection: what is the role of serologic tests before reimplantation? Clin Orthop Relat Res 2009;467(7):1699-705.

https://doi.org/10.1007/s11999-009-0742-9 
23. Chimento GF, Finger S, Barrack RL. Gram stain detection of infection during revision arthroplasty. J Bone Joint Surg Br 1996;78(5):838-9. PMID: 8836084

24. Janz V, Schoon J, Morgenstern C, Preininger B, Reinke S, Duda G, et al. Rapid detection of periprosthetic joint infection using a combination of 16s rDNA polymerase chain reaction and lateral flow immunoassay. Bone Joint Res 2018;7(1):12-9. https://doi.org/10.1302/2046-3758.71.BJR-2017-0103.R2

25. Lee YS, Fernando N, Koo K-H, Kim HJ, Vahedi H, Chen AF. What markers best guide the timing of reimplantation in two-stage exchange arthroplasty for PJI? A systematic review and meta-analysis. Clin Orthop Relat Res 2018;476(10):1972-83. https://doi.org/10.1097/01.blo.0000534680.87622.43 